\title{
CONGENITAL AORTIC STENOSIS AND ITS SURGICAL TREATMENT
}

\author{
BY \\ R. M. MARQUIS AND ANDREW LOGAN \\ From the Department of Cardiology of the Royal Infirmary and the Department of Surgery of the University, \\ Edinburgh \\ Received November 20, 1954
}

The purpose of this paper is to assess the place and timing of surgery in the treatment of aortic stenosis of congenital origin. The diagnosis of aortic stenosis is readily made at the bedside and the clinical features are well known (Levine, 1945; Kiloh, 1950; Campbell and Kauntze, 1953). Its congenital origin is more difficult to substantiate. In the hope of excluding cases of acquired stenosis, we consider here only those patients in whom heart disease was recognized in infancy, or, at latest, on their first routine school medical examination at about five years of age, or in whom the site of stenosis was sub-aortic. Twenty-eight such patients form the basis of this review (Table I): their ages ranged from birth to 25 years. The length of follow-up extended in some instances to ten years and, excluding two infants, averaged nearly four years. Aortic incompetence was also present in six patients and the adult type of coarctation of the aorta in three others. Five patients died as a result of the lesion during the period of follow-up; two in infancy, two before puberty, and one in his middle teens. In six others the stenosis was considered sufficiently severe to justify aortic valvotomy.

\section{Natural History of Aortic Stenosis}

The natural history of aortic stenosis is subject to wide variation depending on the severity of the stenosis and the ætiology of the lesion. Acquired aortic stenosis is common both as a result of generalized rheumatic heart disease and as a degenerative state of the aortic valve. The former type is usually recognized from the presence of other valvular flaws, and in the latter type the slow development of the signs of aortic stenosis (Levine, 1949) and the insidious advance of gross cardiac hypertrophy (Dry and Willius, 1939) combine to suggest that the stenosis develops very gradually. The prognosis in rheumatic aortic stenosis follows that of rheumatic heart disease in general and is subject to the same variation. The outlook in degenerative aortic stenosis is good and patients with this lesion may reach old age without disability (Anderson et al., 1952).

Congenital aortic stenosis rarely presents with symptoms and the recognition of heart disease is usually dependent on routine examination performed for some other reason. Congenital lesions with striking signs seldom escape recognition in childhood. In contrast to the soft murmur present early in the course of acquired aortic stenosis, which may be dismissed as benign (Levine, 1949), the basal murmur of congenital stenosis is clearly organic. It may be some years before a thrill in the neck or in the aortic area leads to a precise diagnosis and at first the aortic thrill may be palpable only when the child leans forward with the breath held in expiration. The apical impulse may be normal or may have the typical thrust of left ventricular hypertrophy or may be deceptively abrupt suggesting hypertrophy of the right ventricle; there is no increase of systolic pulsation at the left sternal margin. The first heart sound at the lower left sternal margin and out to the apex is commonly split. The aortic second sound and the pulse pressure are usually within normal limits. 


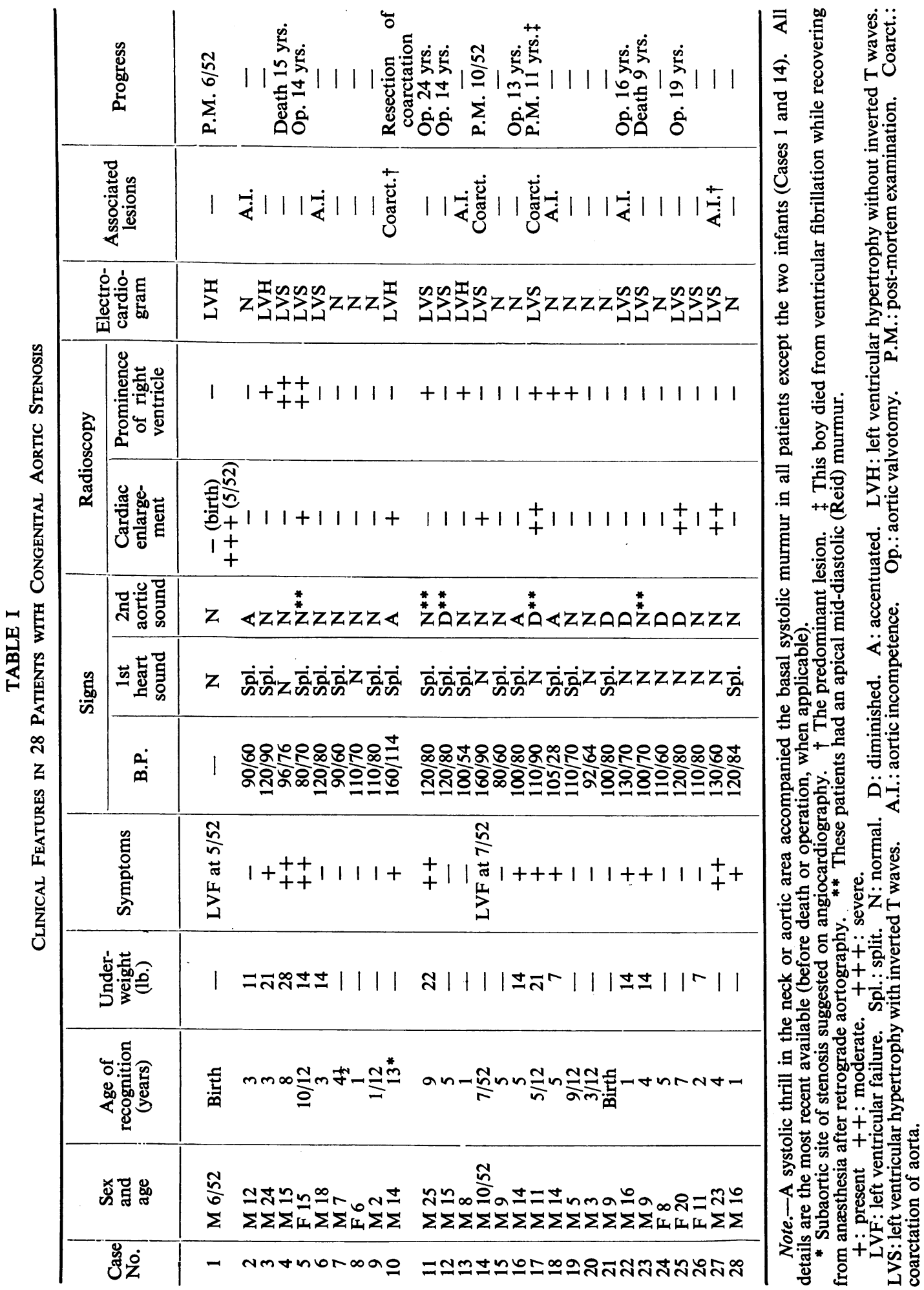


As the years advance the development of a faint blowing aortic diastolic murmur is not uncommon and is probably secondary to increasing rigidity of the deformed valve cusps. Taussig (1947) has emphasized how this evolution contrasts with that in rheumatic aortic stenosis in which the primary lesion is usually incompetence. In the congenital malformation there are seldom peripheral signs of the valvular incompetence but their presence does not exclude a congenital origin. Congenital aortic incompetence is well recognized in coarctation of the aorta, and one of us has seen on routine examination a boy of three years with very free aortic incompetence who had no disability and no history of previous illness, rheumatic or otherwise.

The electrocardiogram is usually normal but may show left ventricular hypertrophy. Radioscopy confirms the absence of cardiac enlargement. Prominence of the ascending aorta is common, but may not be obvious in the younger age group. By the time school years are reached, enlargement of the left ventricle is usually apparent under the X-ray screen in the left anterior oblique position.

The well-being and lack of symptoms in most cases of isolated aortic stenosis, whether encountered in childhood or in adult life and whether the stenosis is mild or severe, has led to the widespread impression that the prognosis in the congenital lesion is good (Grisham et al., 1947; Kiloh, 1950; Campbell and Kauntze, 1953). This is not always so. Congenital aortic stenosis sometimes leads to death in childhood and the particular liability of this lesion to cause sudden death is well recognized (Brown, 1950). The course in the 28 patients in the present series demonstrates that the outlook in congenital aortic stenosis can be serious. The prognosis in mild cases is altogether different from that in severe cases and, as in pulmonary stenosis (Abrahams and Wood, 1951), distinction between the two groups is all-important.

\section{ASSESSMENT OF SEVERITY}

Circulatory Considerations. Assessment of the severity depends on understanding the way in which severe aortic stenosis affects the circulation. A rise of left ventricular pressure and the left ventricular hypertrophy that soon follows combine to maintain cardiac compensation in spite of the obstruction at the aortic orifice. When compensation is complete, the cardiac output is not decreased, arterial pressures are within normal limits, and venous and pulmonary congestion are absent. The heart rate is generally slow and on radioscopy the ventricular action is seen to have a deliberate and purposeful character. Much less stenosis than is necessary to affect the systolic discharge from the left ventricle is sufficient to produce a loud systolic murmur. If the stenosis is severe, and the left ventricular hypertension does not overcome the stenosis, the pressure rises in the left atrium and in the pulmonary circuit. This elevated pressure necessitates a rise of right ventricular pressure which may in turn lead to right ventricular hypertrophy. These circulatory changes have been clearly demonstrated in experimental animals (Wiggers, 1949) and are evident clinically, angiocardiographically, and on cardiac catheterization in man. Direct measurement of the left ventricular pressure at operation (Campbell and Kauntze, 1953) has revealed pressures as high as $216 / 36 \mathrm{~mm}$. Hg. The effects of these pressures on the heart muscle are evident post mortem in enormous hypertrophy of the left ventricle and significant hypertrophy of the right ventricle.

The circulatory changes emphasize three major factors in the assessment of the severity of the aortic obstruction.

(a) By increased force of contraction, compensation is maintained and symptoms are minimal. The presence of symptoms suggests that the stenosis is severe and compensation inadequate.

(b) Hypertrophy alone seldom leads to sufficient cardiac enlargement for clinical or radiological detection. Clinical enlargement of the heart is usually due to dilatation, and its presence when there is no associated aortic incompetence suggests that hypertrophy alone has proved inadequate and that the stenosis must be severe.

(c) There is no evidence that a congenitally stenosed orifice gets larger with the increasing demands of a growing child. With an orifice of fixed size, compensation that is adequate in early 
childhood may become inadequate as body growth proceeds. Stenosis that appears mild in early childhood may prove severe before adult life is reached.

Symptoms. The onset of symptoms, as in isolated pulmonary stenosis, is late in the natural history of aortic stenosis. "The immunity from suffering is due to the great increase of power in the heart, and especially the left ventricle, so as to enable it to maintain the circulation " (Peacock, 1868). Even slight disability is significant. The commonest complaint is a tendency to fatigue by the end of the day. Exertional dyspnoea is seldom sufficient to attract attention and its absence does not exclude severe stenosis. Lewes (1951) has stressed the severe prognostic significance of symptoms in aortic stenosis and Marvin and Sullivan (1935) have suggested that cardiac syncope is a precursor of sudden death. Cardiac syncope is always ominous although not necessarily incompatible with several years of life even in growing children. In Case 23 there were three minor episodes of syncope on exertion between 3 years and the attack in which death occurred at 9 years. In Case 4 dizziness on severe exertion had been present for a year and the first major episode of syncope occurred five months before sudden death at 15 years of age. In older patients with aortic stenosis, angina of effort is common and may be secondary to severe stenosis or to advanced coronary atherosclerosis in association with mild stenosis (Dry and Willius, 1939; Anderson et al., 1952). Angina was present in only one of the present series (Case 3). In him it was mild, and considerable exertion was required to produce a momentary sensation of substernal constriction. A vigorous exercise test, however, produced striking ST-T wave changes (Fig. 1). Similar changes occurred in Case 16 without the production of pain. The frequency of this type of cardiographic change in aortic stenosis and its prognostic value are not yet known. Lewes (1951) found angina an indication of severe stenosis and that patients subject to it were liable to sudden death. Hæmoptysis is a rare presenting symptom in aortic stenosis, but occurred in one patient in the present series (Case 11) who had other indications of very severe stenosis. It has been observed also in a patient with severe coarctation of the aorta whose pulmonary arterial pressure on cardiac catheterization ranged from $35-50 / 15 \mathrm{~mm}$. Hg. Like ischæmic pain hæmoptysis suggests severe stenosis but is too uncommon in the younger age group for a firm conclusion on its prognostic significance.

Signs. As a general rule, signs appear earlier and are of much greater value than symptoms in the assessment of the severity of aortic stenosis. Only by the recognition of this fact can sudden death be anticipated and prevented by timely surgery. In general appearance the patient with severe aortic stenosis tends to be pale, thin, and poorly developed and may be as much as $28 \mathrm{lb}$. under average weight in the early teens (Case 4). Twelve of the present series were more than $7 \mathrm{lb}$. under the standard weight for their age. It is unusual for the patient with severe congenital aortic stenosis to be of heavy muscular build, but there are exceptions (Case 12). Brown (1950) mentions pallor and small stature as common features in aortic stenosis, but states that these characteristics may be lacking when the stenosis is mild. The build of the patient bears a much closer relationship to the severity of the lesion than it does in coarctation of the aorta.

The pulse and blood pressure are unreliable signs in the diagnosis of aortic stenosis (Kiloh, 1950; Lewes, 1951) but are of undoubted value in the recognition of the severity of the malformation. The smallness of the pulse pressure depends upon the degree of the stenosis, although the pulse pressure is often larger than might be expected (Wiggers, 1949). A normal pulse pressure on sphygmomanometry does not exclude severe stenosis, but a delay in the upstoke of the pulse wave revealed on intra-arterial pressure tracings (Fig. 3) is probably a reliable guide to the severity of the stenosis. A true anacrotic notch is a rare clinical finding. Wiggers (1949) has shown experimentally that the aortic orifice has to be reduced to one-quarter of its normal size before the form of the arterial pulse wave is affected, and that the more severe the stenosis, the lower the anacrotic notch occurs on the upstroke. These observations emphasize the significance of the form of the intra-arterial wave in this malformation.

The type of præcordial pulsation and the character of the apical impulse are of little assistance in 


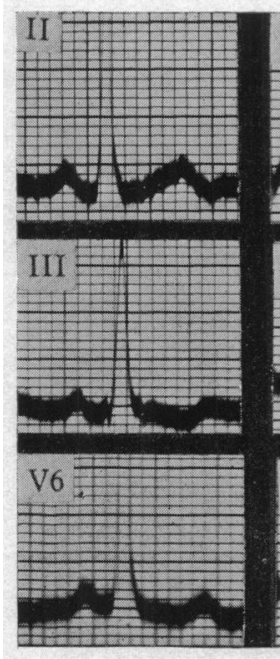

A

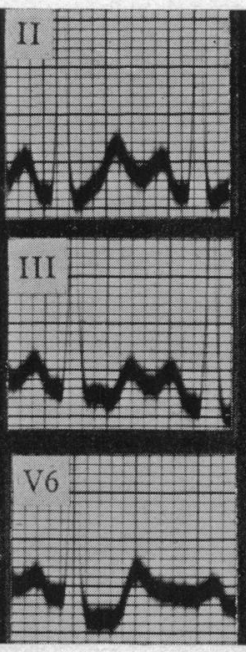

B

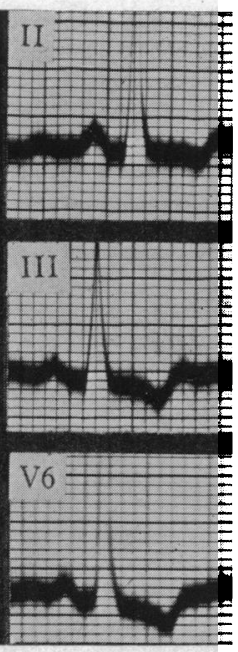

$\mathrm{C}$

FIG. 1.-Electrocardiogram of Case 3 at 24 years of age. (A) At rest. (B) Immediately after strenuous exercise-17,280 $\mathrm{ft}$. $1 \mathrm{~b}$. in three minutes-S-T depression in V6. (C) Five minutes after exerciseinversion of the T wave in leads II, III, and V6.

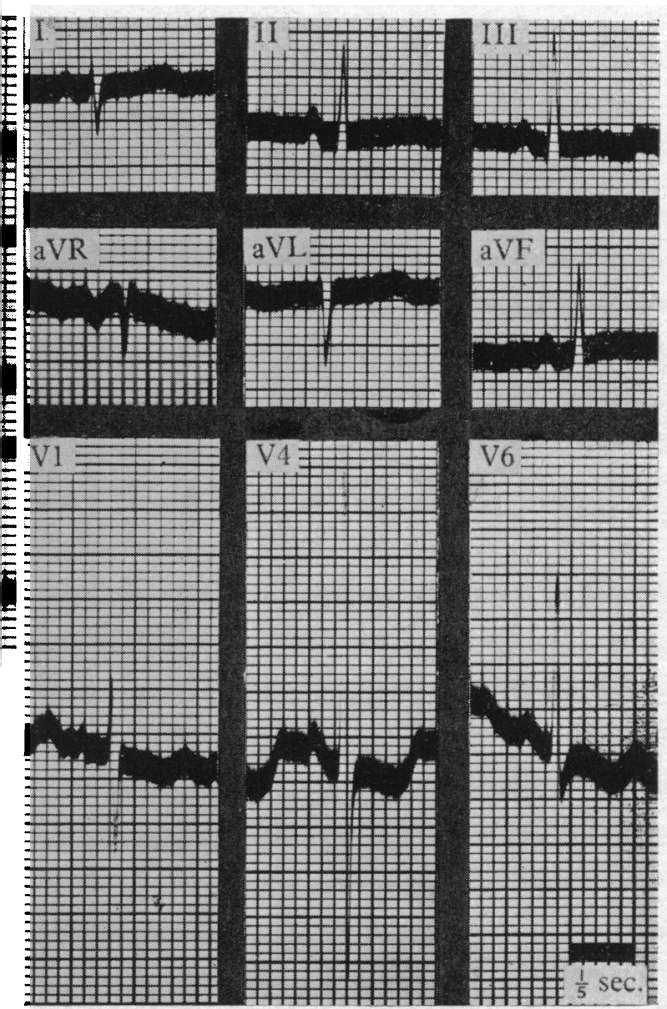

FIG. 2.-Electrocardiogram of Case 1 at three days of age. Right axis deviation. Early evidence of left ventricular hypertrophy in V4 and V6 in which leads $R$ waves are tall and $T$ waves diphasic.

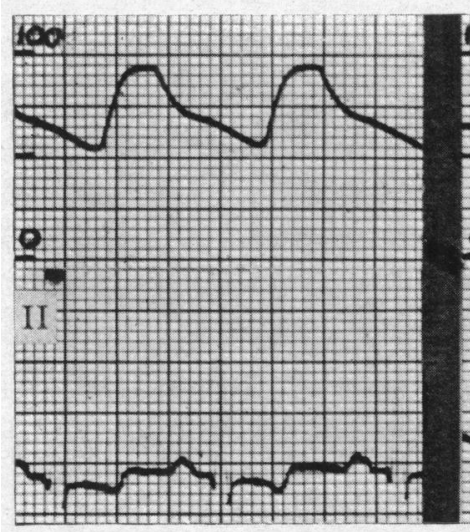

A

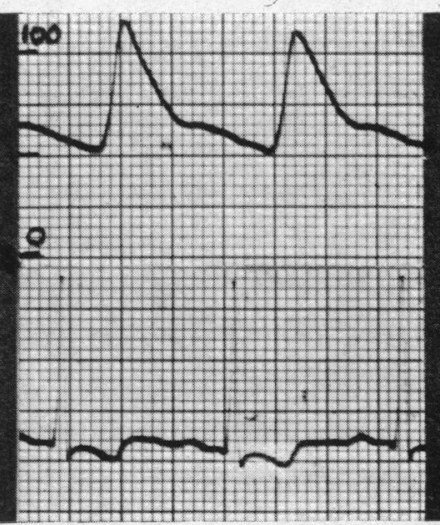

B

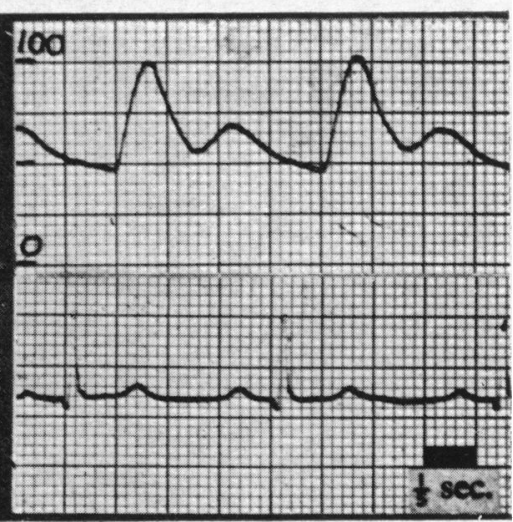

C

Fig. 3.- Intra-arterial brachial pulse wave in Case 11. (A) Before valvotomy; B.P. 95/45, upstroke $0.24 \mathrm{sec}$. (B) Three weeks after valvotomy; B.P. 110/50, upstroke $0.10 \mathrm{sec}$. (C) Normal control; B.P. $100 / 45$, upstroke $0 \cdot 12 \mathrm{sec}$. 
either the diagnosis or the assessment of aortic stenosis of congenital origin. The forceful, heaving impulse found in the older age groups may be conspicuously absent, even when the cardiogram shows extreme left ventricular hypertrophy. The first heart sound at the apex and lower left sternal margin tends to be loud and widely split, but this feature, like the intensity of the basal systolic murmur and thrill, does not bear a constant relationship to the severity of the stenosis. Nevertheless, the finding of a widespread aortic systolic murmur and thrill in early childhood suggests that as growth proceeds the stenosis will be found to be severe. The aortic second sound tends to be diminished in severe aortic stenosis (Dry and Willius, 1939) but is often of normal intensity (Kiloh, 1950; Lewes, 1951; Levine, 1949; Taussig, 1947; Grishman et al., 1947). Diminution of the aortic second sound has proved uncommon in the younger age group of the present series; indeed it has often been loud in the presence of severe stenosis.

A short, rough mid-diastolic murmur of abrupt quality was heard at the apex or just internal to it in five patients (Cases 5,11,12,17, and 23). In none of them was there other clinical evidence of mitral stenosis and in Case 17 the mitral valve was normal post mortem except for marked atheroma (impingement plaque) on the ventricular surface of the medial cusp. In each of these patients there was cardiographic evidence of extreme left ventricular hypertrophy. This murmur was detected on another occasion in a seven-year-old boy with marked hypertension secondary to severe coarctation of the aorta, who also had extreme left ventricular hypertrophy and a normal mitral valve post mortem. This murmur is presumably dynamic in origin and secondary to gross left ventricular hypertrophy and intraventricular hypertension. It disappeared after aortic valvotomy in Cases 5, 11, and 12. We have heard this apical murmur of severe aortic stenosis referred to as Reid's murmur but have been unable to trace the original reference.

\section{Ancillary Investigations}

Electrocardiographic evidence of left ventricular hypertrophy has proved the most reliable single sign of severe aortic stenosis. The development of left ventricular hypertrophy closely parallels the development of right ventricular hypertrophy in pulmonary stenosis (Marquis, 1951). The earlier in childhood that this appears and the more rapid its progression, the more severe the stenosis and the worse the prognosis. This is impressively demonstrated in those patients of the present series in whom aortic stenosis proved fatal. In Case 1 there was already evidence of left ventricular hypertrophy three days after birth (Fig. 2) and in Case 14 there was deep T wave inversion and S-T depression in the left chest leads at seven weeks of age. In Case 23, left ventricular hypertrophy developed between five and eight years of age (Fig. 4). In Case 17, the hypertrophy was of extreme degree at five years of age, and in Case 4 (Fig. 5) at 11 years of age. No patient died without the development of inverted $T$ waves in the left chest leads except the infant (Case 1), in whom the only cardiogram recorded was at the age of three days. Sixteen out of the whole series showed cardiographic evidence of left ventricular hypertrophy, and in twelve of them there was $T$ wave inversion in leads facing the epicardial surface of the left ventricle. The development of left ventricular hypertrophy in adult life, after growth has ceased and the cardiac output is no longer increasing with age, is probably of less immediate prognostic significance, but is an indication for full investigation. Abnormal ballistocardiograms, grades 2 and 3 as described by Brown et al. (1950), are also frequent in aortic stenosis. Our experience is inadequate for a proper appreciation of their value in assessing severity.

The infrequency of cardiac enlargement on radioscopy has been stressed by Kiloh (1950) and Campbell and Kauntze (1953). In contrast to the cardiographic pattern, there is little or no increase in heart size or in the size of the left ventricle with the passage of years. This general rule obtains even in the presence of severe stenosis; there was no increase in the size of the heart during the last year of life in Cases 4 and 23. In the absence of significant aortic incompetence, marked enlargement is due to ventricular failure (Fig. 6) or to a quite exceptional degree of hypertrophy. It is always indicative of very severe stenosis and of very poor immediate prognosis. The shape of the 


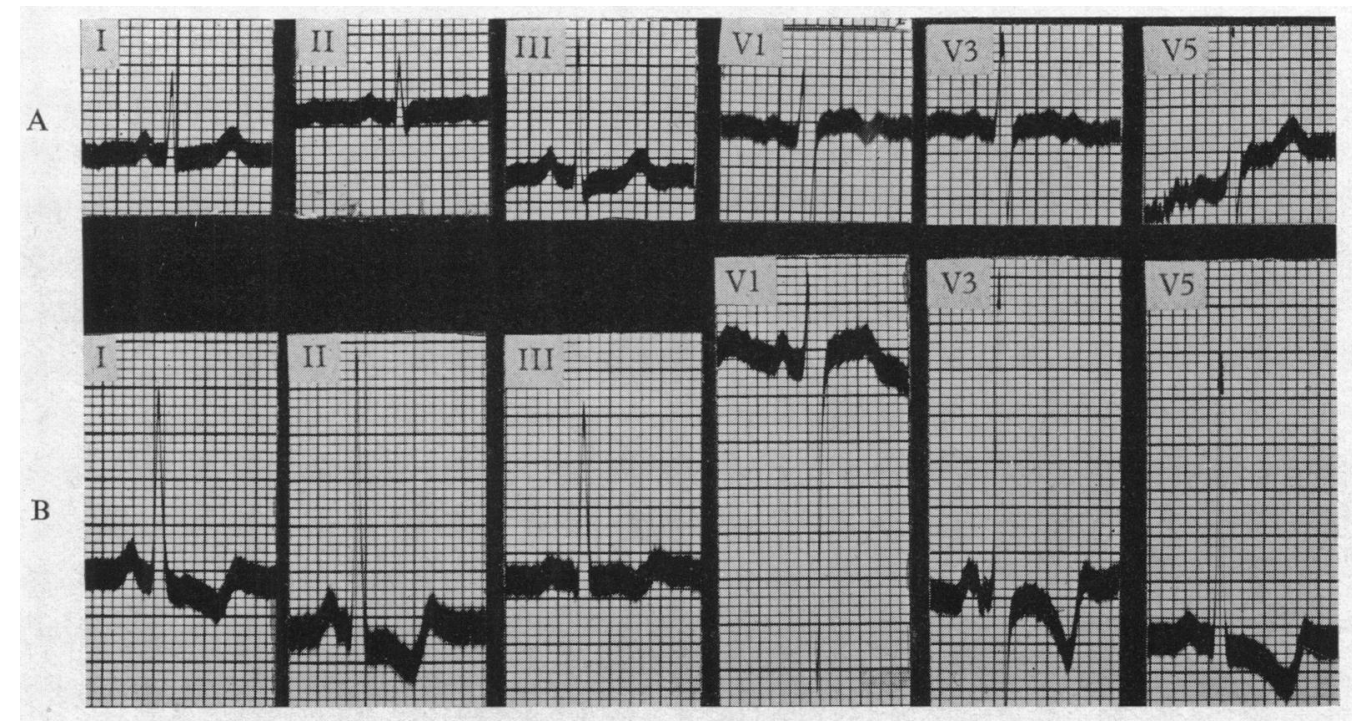

FIG. 4.-Electrocardiogram of Case 23. (A) Within normal limits at 5 years of age. (B) Left ventricular hypertrophy and strain at eight years of age.

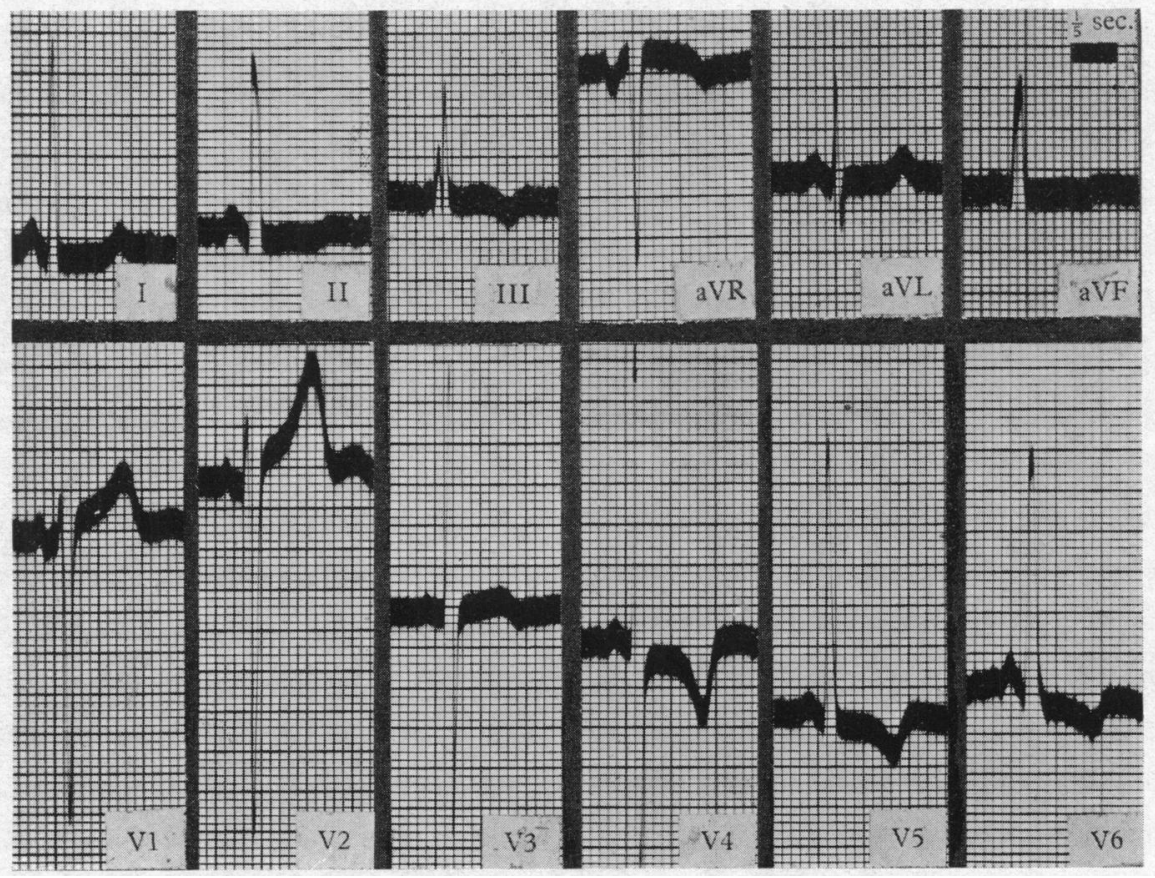

Fig. 5.-Electrocardiogram of Case 4 shortly before his sudden death at 15 years of age. No axis deviation. Extreme left ventricular hypertrophy and strain. 
cardiovascular shadow may also be of help in assessing the severity of the stenosis, and the strain it is imposing upon the circulation, by revealing prominence of the right ventricle in the left anterior oblique position (Fig. 7). This was well seen in eight cases, the presence of right ventricular hypertrophy being confimed post mortem in Case 16. Right ventricular hypertrophy in aortic stenosis was noted at autopsy by Peacock (1868), de Veer (1938), and Campbell and Kauntze (1953). Prominence of the right ventricle on radioscopy is less common in older patients with aortic stenosis, possibly because embarrassment of the right ventricle (Bernheim, 1910) leads to failure and death before the pressure in the pulmonary circuit rises. Calcification of the aortic valve was not seen on radioscopy in any of the patients in the present series. This was probably due to their youth (Campbell and Kauntze, 1953) for calcification bears little relation to the severity of the stenosis (Dry and Willius, 1939).

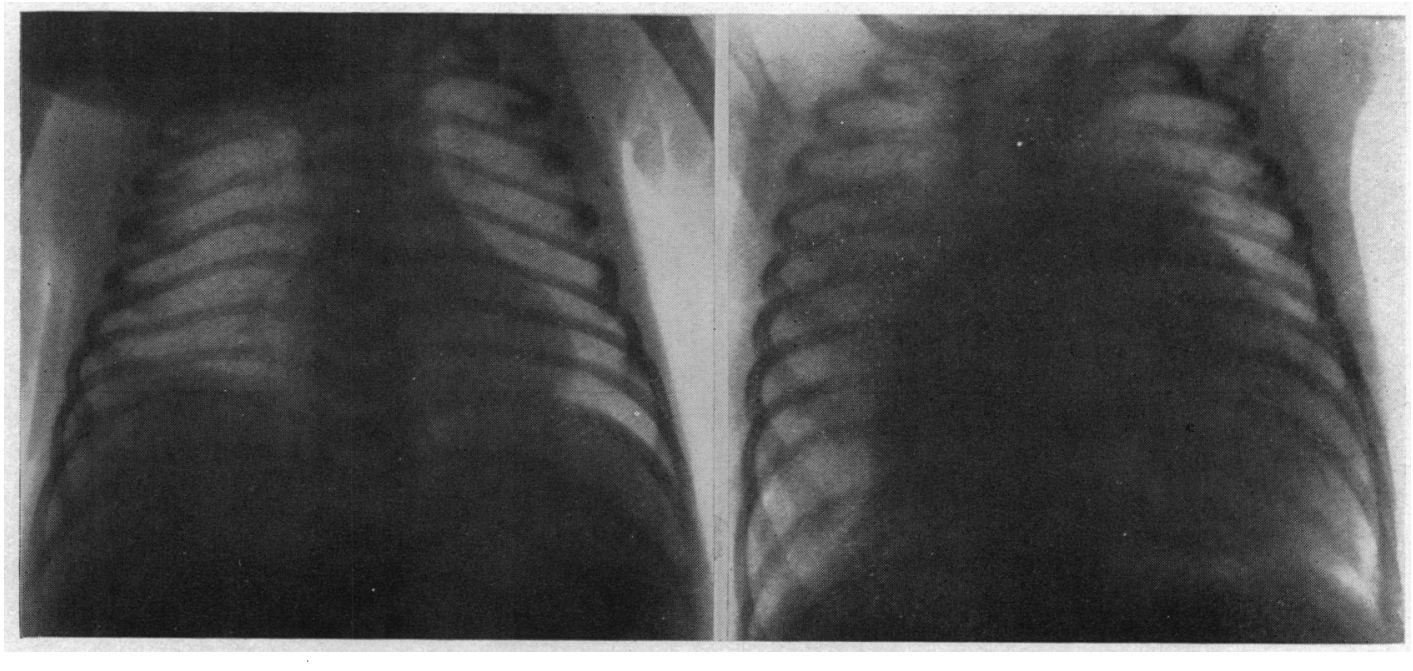

A

\section{B}

FIG. 6.-Radiograph (anterior) of Case 1. (A) At three days of age. Heart size within normal limits. (B) At five weeks of age. Gross enlargement of the heart with central congestion of the lung fields.

Angiocardiographic examination was performed in 10 of the series as part of their assessment for surgical treatment. This investigation was undertaken in an attempt to exclude subaortic stenosis. In only one was subaortic stenosis (Fig. 9) suggested, and in the remainder the contrast medium was clearly seen filling the left ventricle up to the origin of the aorta without apparent narrowing of the outflow tract; the lateral position was found of most value is displaying this (Fig. 8). Although no evidence of subaortic obstruction was encountered at operation in the six patients upon whom subsequent valvotomy was performed, we cannot be certain that this appearance excludes its presence. The angiocardiograms suggested delayed clearing of the left side of the heart in five patients (Cases 3,11,12,17, and 22) in so far as the left ventricle was not clear of contrast medium within six seconds of first opacification. In only one (Case 5) was there indisputable hold-up throughout the circulation (Fig. 8 and 10). This is a visual demonstration of cardiac insufficiency, and illustrates clearly the effect that aortic stenosis can have on the circulation: it constitutes certain evidence of severe stenosis. Cardiac catheterization has not been performed as a routine in the investigation of these patients before operation but the small pulmonary arteries in Case 17 showed similar changes post mortem to those seen in pulmonary hypertension secondary to mitral stenosis. A raised pulmonary arterial pressure was present in two of the cases reported by Campbell and Kauntze (1953) and as a manifestation of left ventricular insufficiency this is probably another sign of severe aortic stenosis. 


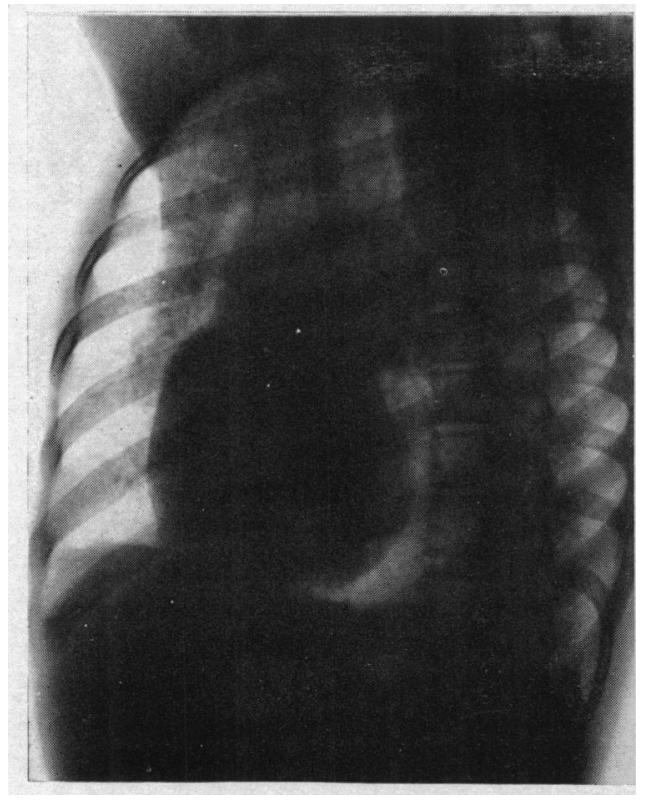

FIG. 7.-Radiograph (left anterior oblique) of Case 4 at 15 years of age, showing prominence of the right as well as of the left ventricle.

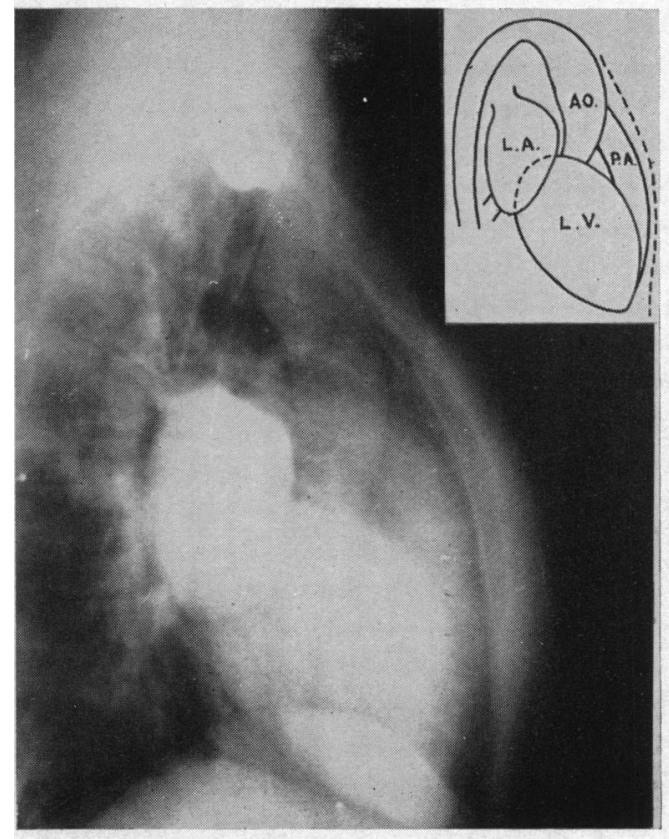

FIG. 8.-Angiocardiogram (lateral) at 13 seconds of Case 5 before valvotomy. The concentration of the dye in the left ventricle up to the origin of the aorta probably excludes subaortic obstruction. The delayed circulation is well illustrated by the concentration of dye on the left side of the heart, the poor opacification of the aorta and by the persistence of dye in the pulmonary artery.

\section{Surgical Considerations}

If the stenosis is severe, valvotomy may possibly improve the prognosis. The assessment for surgical treatment and the timing of operation require an understanding of the anatomy of the stenosis and its effect upon the myocardium, and also practical experience of operative treatment and the results that may be achieved by aortic valvotomy.

Anatomy of Aortic Stenosis. The anatomy of the stenosis varies according to its ætiology. There are some grounds for expecting cusps fused by rheumatism to separate along the commissures without the production of aortic incompetence (Larzelere and Bailey, 1953; Logan and Turner, 1954). Good post-operative function of the cusps is unlikely in the congenital lesion. In the present series an attempt has been made to consider congenital stenosis only, but it is important to realize that there is no combination of clinical signs that makes this ætiological diagnosis certain. Pathological evidence likewise is seldom valid. The finding of bicuspid valves at necropsy does not imply that any stenosis present is necessarily of congenital origin, for there is no reason to expect acquired stenosis to be confined to valves with three cusps. Indeed, Peacock (1865) considered that congenitally deformed valves have an increased tendency to become diseased.

The distinction between valvular and subaortic stenosis is also difficult. Both types are liable to considerable post-stenotic dilatation of the ascending aorta and the location of the maximum murmur and thrill is unreliable evidence of the site of stenosis. Angiocardiography (Fig. 9) will probably prove of assistance, but there is insufficient evidence to be sure of this. The problem, however, is largely theoretical for subaortic stenosis as an isolated lesion appears to be very uncommon and rarely of sufficient severity to require operative treatment. 


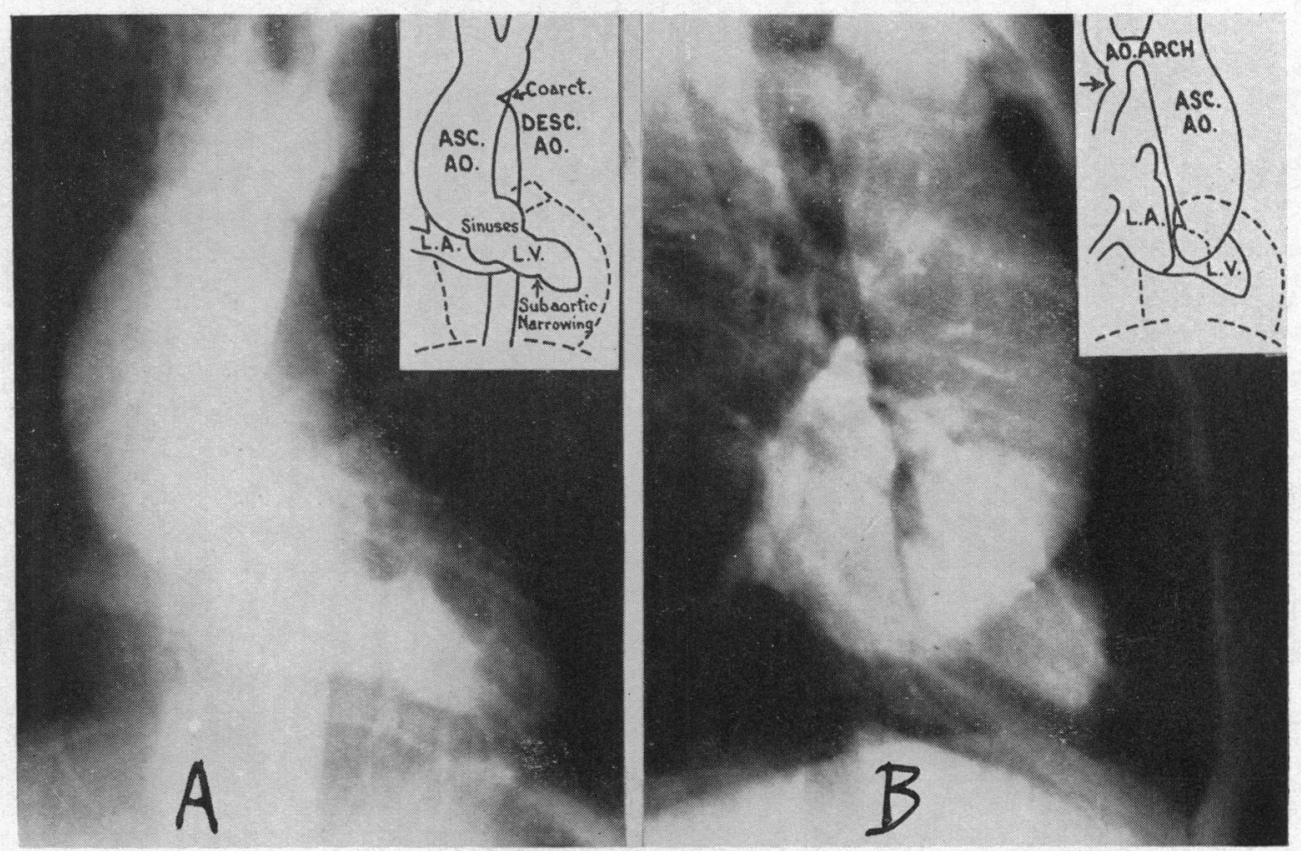

FIG. 9.-Angiocardiograms at 8 seconds of Case 10 at 12 years of age. (A) Anterior. Serial films showed persistence of the area of constriction in the left ventricle during both systole and diastole. (B) Lateral. This view emphasizes the low position of the aortic valve and the dilatation of the ascending aorta also evident in the anterior view. The angiocardiographic appearances suggest mild subaortic stenosis. At operation for the coarctation of the aorta, inspection of the left ventricle revealed no external deformity but a systolic thrill was felt below as well as above the aortic valve.
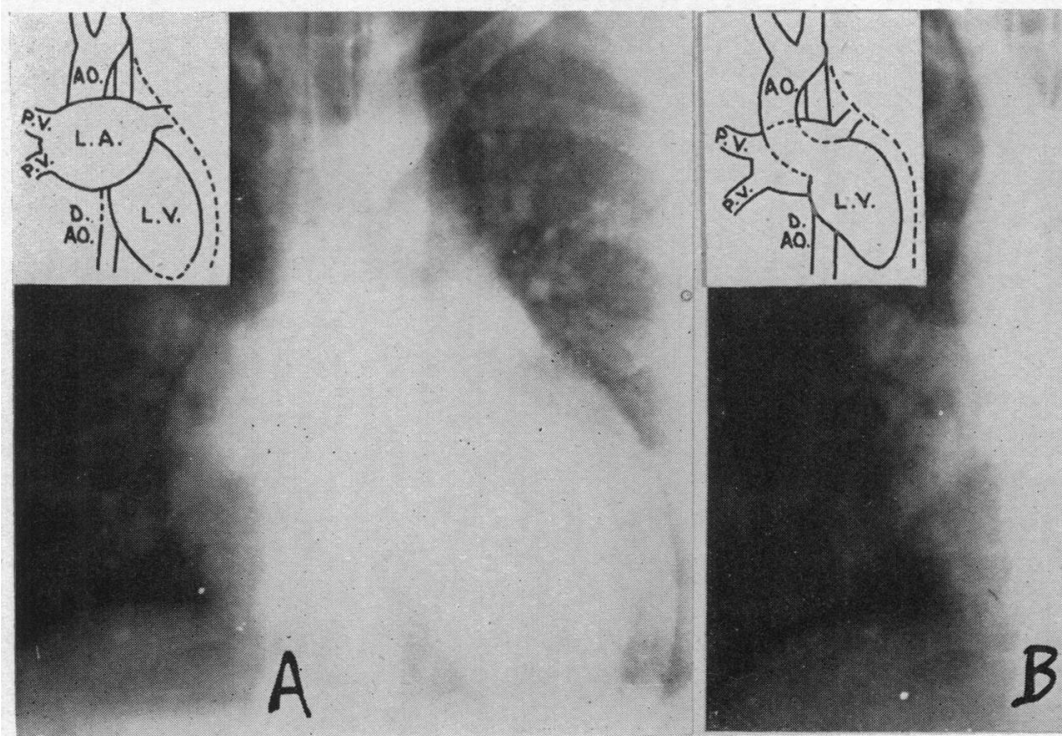

Fig. 10.-Angiocardiograms (anterior) of Case 5. (A) Before valvotomy. At 13 seconds the aorta is still poorly opacified and much less dense than the large left atrium (which dominates the picture) and thick-walled left ventricle. (B) Three weeks after valvotomy. At 7 seconds the aorta is already as dense as the left ventricle. The cavities of the left atrium and left ventricle are smaller than before operation. 
Necropsy findings were available in three patients of the present series, in all of whom the stenosis was severe. In one infant of 10 weeks (Case 14) there were three cusps which were narrow and adherent at their free margins making a cone similar to that of congenital pulmonary stenosis: there was no thickening of the cusps except at their free margins. In the other two patients, an infant of six weeks (Case 1) and a boy of 11 years (Case 17), there were two cusps which were thick, opaque, hard, and fibrosed. The great deformity of this type of valve, illustrated in Fig. 11, is not uncommon in congenital aortic stenosis. The fact that bicuspid valve cusps may be so deformed in infancy (Case 1) suggests that the gross deformity common in older patients is not only the result of long continued trauma. Nevertheless, the traumatic effect of high pressure cannot be ignored; the occurrence of degenerative aortic stenosis emphasizes its importance. The later development of stenosis in rheumatic aortic incompetence and the impression that bicuspid aortic valves are particularly liable to develop stenosis suggest that aortic cusps that are already damaged tend to become stenosed. Some recurrence of the stenosis after valvotomy, therefore, appears probable.

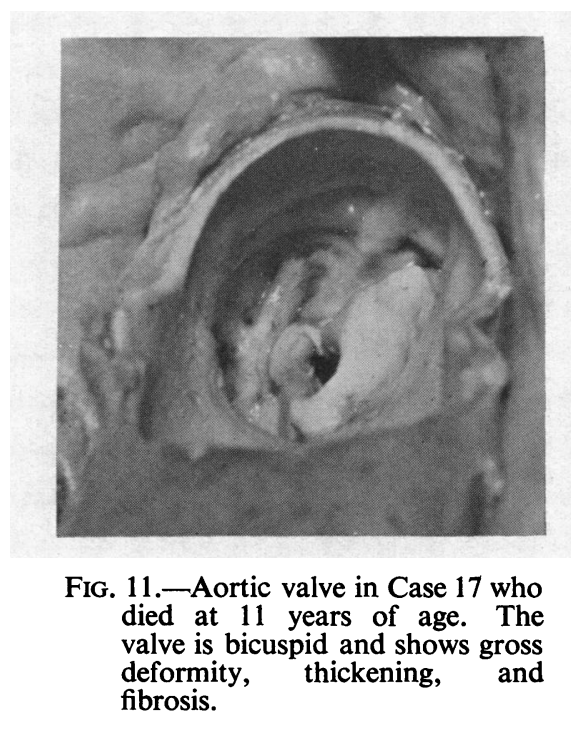

Effect of Aortic Stenosis on Myocardium. The extent and nature of fibrosis of the left ventricle (Fig. 12) found post mortem in an 11-year-old boy (Case 17) is an impressive illustration of the effect of severe aortic stenosis on the myocardium. The fibrosis is a replacement lesion secondary to death of the muscle cells which on examination under high power can be seen distintegrating in the subendocardial half of the myocardium. It is thus quite distinct from the fibrosis seen in chronic myocardial hypertrophy (Harrison and Wood, 1949) and bears a closer relationship to the " zonal ring infarction" described by Fulton (1954). The frequency of such severe myocardial fibrosis in aortic stenosis is not known. The same zonal subendocardial distribution has been seen in a man 49 years old in whom aortic stenosis had been diagnosed first on routine examination at 18 years of age, and in whom the coronary vessels were unusually large and healthy. In both these patients the myocardial fibrosis was confined to the left ventricle although in one of them (Case 17) there was also hypertrophy of the right ventricle. This localization of the fibrosis to the left ventricle is the counterpart of the fibrosis of the right ventricle in pulmonary stenosis (Allenby and Campbell, 1949). It emphasizes the importance of outlet stenosis in the causation of the fibrosis.

The occurrence of anginal pain in both forms of stenosis, their common liability to cause sudden death, the necrobiosis of the muscle cells, the subendocardial distribution of the fibrosis and the electrocardiographic changes on exercise (Fig. 1) combine to suggest that the fibrosis may be secon- 
dary to ischæmic destruction of the muscle cells. There is much experimental work to support this suggestion (Green, 1936; Johnson and di Palma, 1939; Wiggers, 1949), but in the absence of accurate assessment of the phasic coronary blood flow through the intra-mural vessels (Gregg, 1946), the evidence is not conclusive.

Aortic Valvotomy. Bailey has pioneered the transventricular approach to the aortic valve, and has shown division of the commissures to be a feasible procedure in aortic stenosis of rheumatic origin (Larzelere and Bailey, 1953). If good results are to be obtained in congenital stenosis, operation should anticipate the development of myocardial fibrosis and calcification of the valve. In theory, therefore, valvotomy should be performed as soon as the severity of the stenosis is certain. In practice, the position is complicated by the risks of the procedure.

The value of operation and the extent of its application can be determined only by experience. A short pilot study was therefore planned. Six patients (Cases 5, 11, 12, 16, 22, and 25), in whom the clinical picture suggested in different ways a severe degree of aortic stenosis, were selected for operation. In each case the approach was through the left ventricular wall, and an expanding dilator introduced into the aortic orifice was opened to its full extent $(4 \mathrm{~cm}$.) in two or more directions without prior incision of the valve. It was thought probable that division in the best line of cleavage was as likely to be achieved in this way as by the more elaborate technique now advocated in acquired stenosis (Bailey et al., 1954).

Case 5. Female, 14 years. Slight dyspnœa and fatigue since five years. Episode of ankle swelling and cardiac syncope three months before operation.

Tearing sensation as dilator opened in aortic orifice. Immediate decrease in heart size. Uneventful post-operative course. Angiocardiography showed correction of delayed circulation (Fig. 8 and 10). Faint aortic diastolic murmur first detected three months after operation. Symptom-free six months after operation.

Case 11. Male, 24 years. Slight dyspnœa since 14 and worse since 22 years. Extreme left ventricular hypertrophy in first cardiogram at 20 years.

No sensation of tearing as dilator opened. Slight post-operative aortic incompetence with increase in heart size. Ballistocardiographic regression from grade 3 to grade 1 abnormality. Less dyspnœic but not symptom-free six months after operation.

Case 12. Male, 14 years. No disability but cardiographic evidence of marked left ventricular hypertrophy.

Sensation of tearing as dilator opened. Slight post-operative aortic incompetence with increase in heart size. Ballistocardiographic regression from grade 3 to grade 1 abnormality (Fig. 13). Increased energy six months after operation in spite of progression of aortic incompetence.

Case 16. Male, 13 years. Easily tired since five years. No cardiographic evidence of left ventricular hypertrophy but ischæmic changes on exertion and grade 3 abnormality of ballistocardiogram.

Sensation of calcification at aortic valve with tearing as dilator opened. Diastolic thrill of aortic incompetence immediately after valvotomy. Post-operative course complicated by gross cardiac enlargement and portal and pulmonary congestion. Less easily tired and more robust six months after operation in spite of free aortic incompetence (Fig. 14).

Case 22. Male, 16 years. Never strong. Slight dyspnœa since 13 years with development of cardiographic evidence of left ventricular hypertrophy between 14 and 16 years.

Tearing sensation as dilator opened with immediate thrill of increased aortic incompetence. Moderate post-operative cardiac enlargement in spite of prophylactic digitalization. Stronger and less dyspnœic six months after operation in spite of free aortic incompetence.

Case 25. Female, 19 years. No disability. Keen sportswoman. Cardiographic evidence of marked left ventricular hypertrophy in first record at 16 years.

No sensation of tearing when dilator opened, but muscular resistance at full expansion. Uneventful post-operative course. Increased energy six months after operation. 


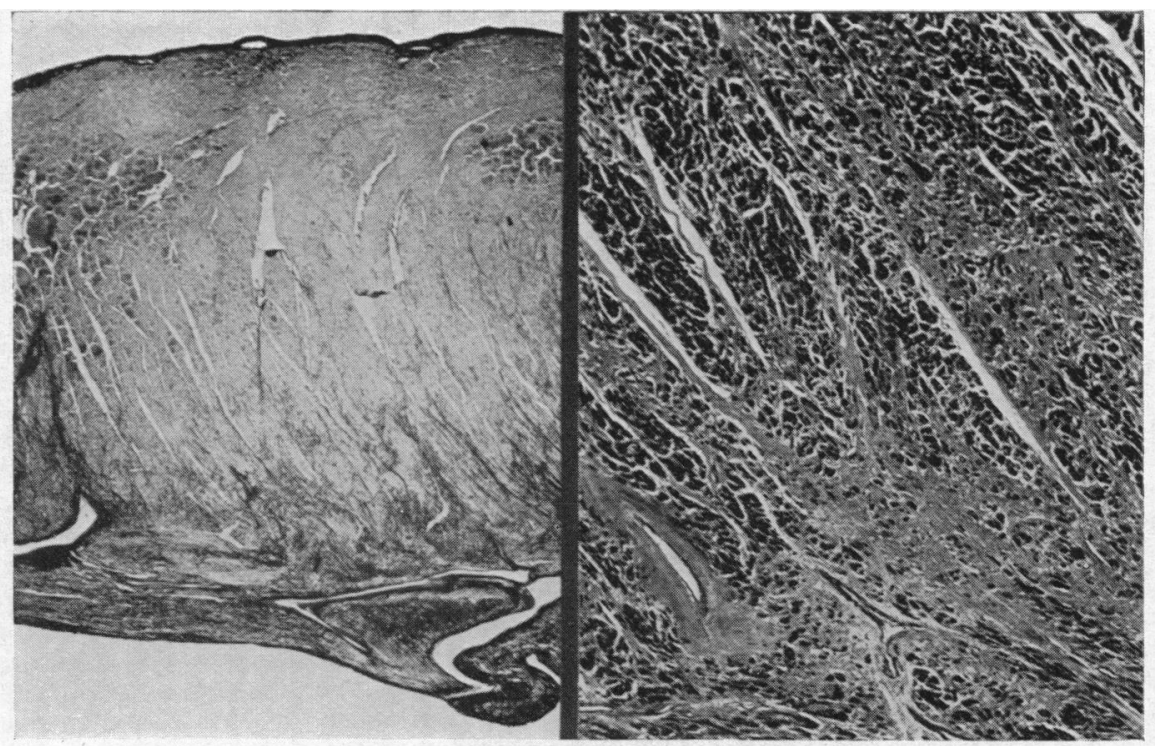

A

B

FIG. 12.-Photomicrograph of myocardium of left ventricle in Case 17 at 11 years of age. (A) full thickness of ventricular wall $(\times 5$. Mallory's stain). There is replacement fibrosis which is greatest in the subendocardial zone. (B) The extent of the fibrosis at the junction of middle and subendocardial thirds ( $\times 25$. Masson's stain).

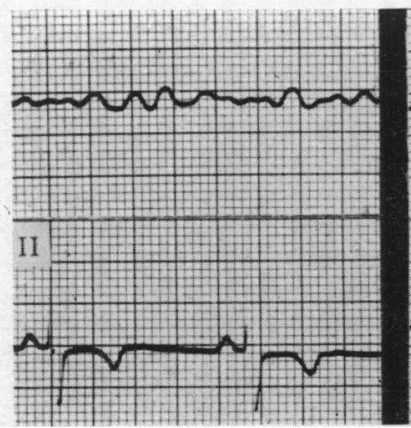

A

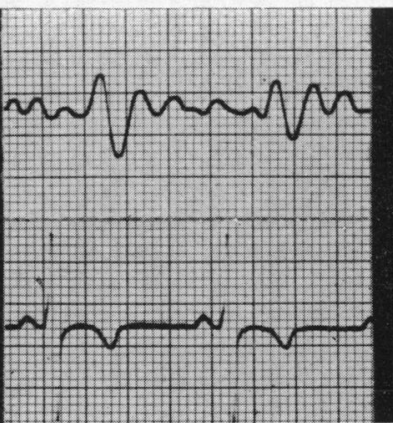

B

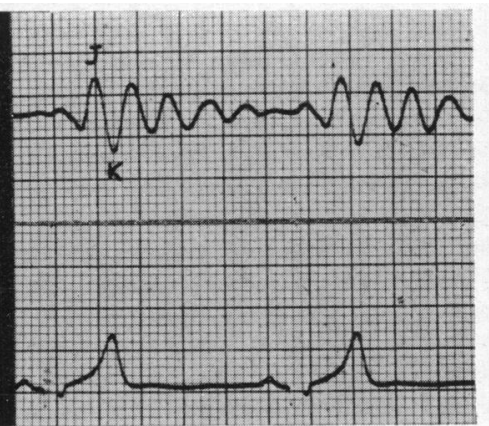

C

FIG. 13.-Ballistocardiogram (inspiration with filter in) of Case 12. (A) Before valvotomy: grade 3 abnormality; the complexes remain identifiable but their amplitude is small. (B) Three weeks after valvotomy: grade 1 abnormality; the striking increase in the $\mathrm{K}$ wave may be partially due to aortic incompetence produced by operation. (C) Normal control. Ballistocardiograms recorded by the method described by Jacobs (1954).

\section{RESULTS OF SURGERY}

The results in the six patients (Table II) in this pilot study have been fairly satisfactory. None died as a result of the operation, three have received undoubted benefit, and there is no certain evidence during over six months' observation that any patient has been made worse.

The reduction in the intensity of the signs of aortic stenosis has been striking in all patients. Where a systolic thrill is still detectable, this has become localized and difficult to feel. Although 


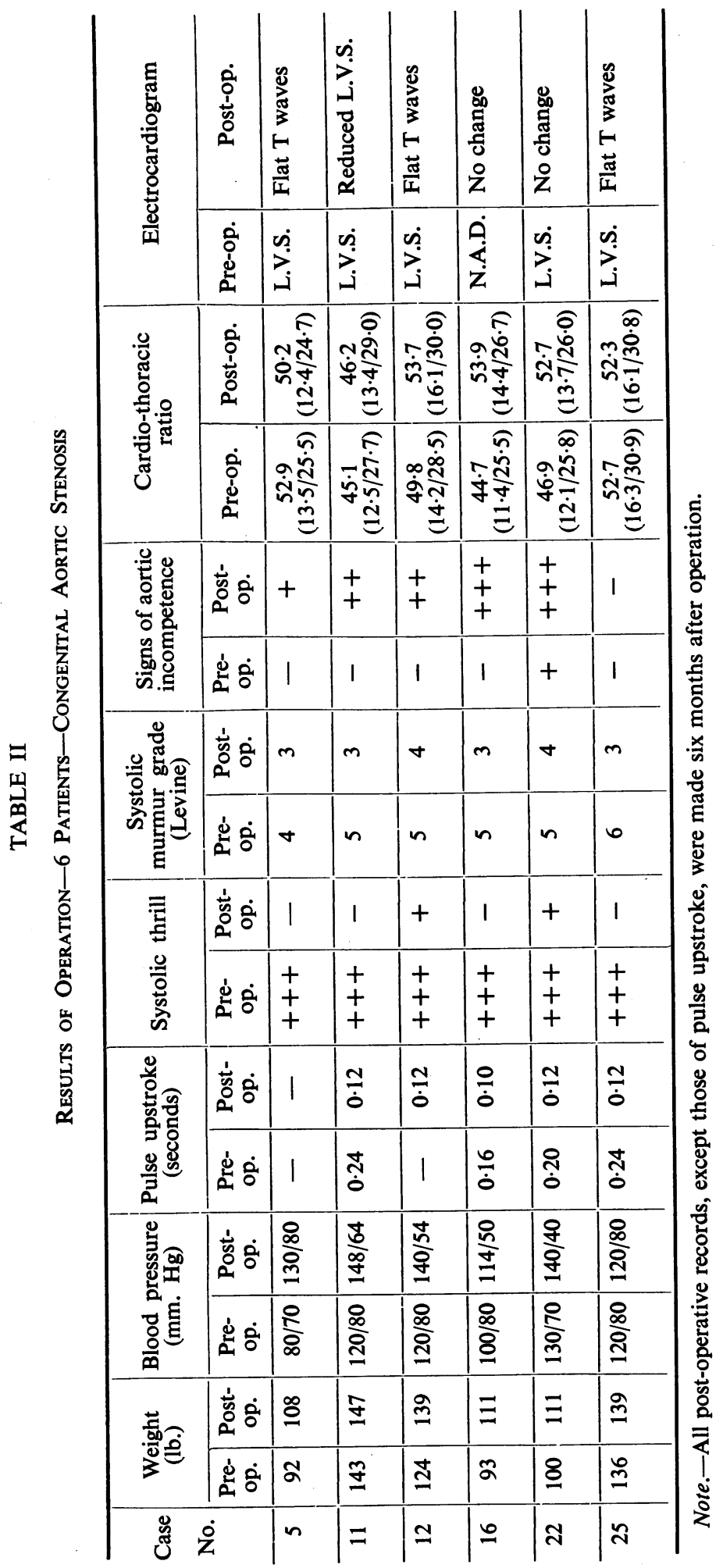


the intensity of the systolic murmur has seldom been reduced by more than one grade, it has become localized to the aortic area. Those who had Reid murmurs have them no longer. Where pulse tracings have been recorded after operation, the upstroke of the wave has returned to normal. In the one patient in whom no such tracing was taken, the blood pressure has increased from $80 / 70$ to $130 / 80 \mathrm{~mm}$. Hg. These changes are more than is usual after pulmonary valvotomy; it is reasonable to assume that the actual stenosis has been as satisfactorily relieved and that the functional relief has been greater. The disappearance of symptoms in one patient, their partial relief in another, and the sensation of increased well-being in those who had few symptoms before operation suggest that there has been some improvement of cardiac function in them all. Reduced electrocardiographic evidence of left ventricular strain (Fig. 15), ballistocardiographic improvement (Fig. 13), reduction of heart size with disappearance of the delayed circulation on angiocardiography in one patient (Fig. 10), and an average weight increase of $11 \mathrm{lb}$. during the first six months after operation add support to the suggestion of improved cardiac function.

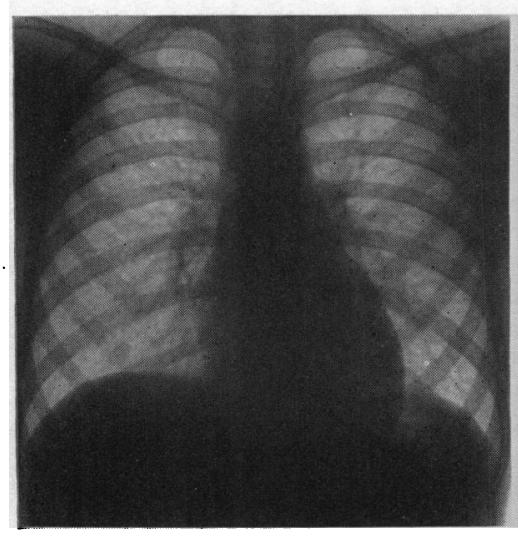

A

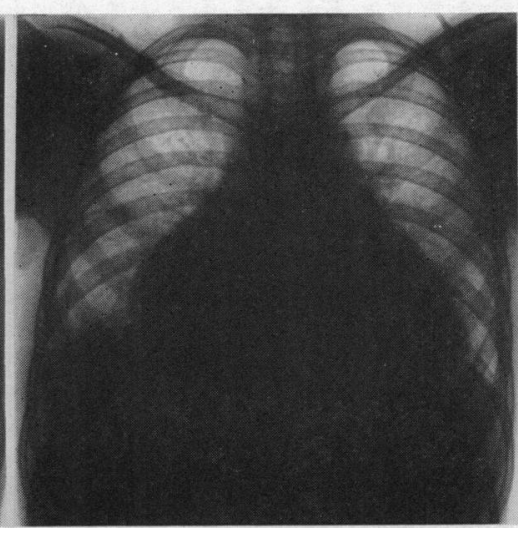

B

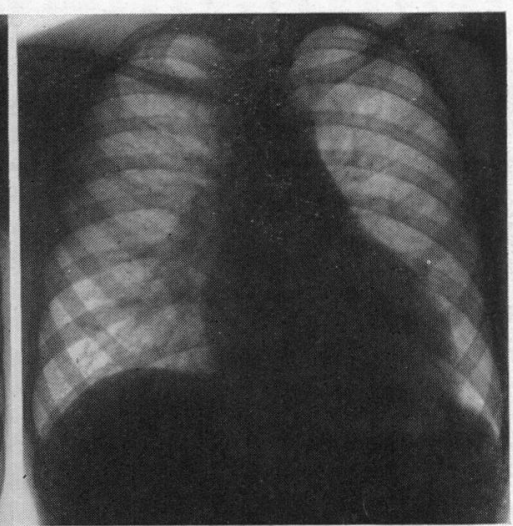

C

Fig. 14.-Radiograph (anterior) of Case 16. (A) Before valvotomy showing no enlargement (c.t.r. 44.7). (B) Three weeks after valvotomy with gross enlargement suggesting pericardial effusion. Paracentesis produced less than $2 \mathrm{ml}$. of slightly blood-stained fluid (c.t.r. 72-4). (C) Six months after valvotomy with moderate enlargement (c.t.r. 53.9).

The manifestations of benefit must be weighed against the effects of aortic incompetence which was produced in four patients and increased in a fifth. This high incidence is not fortuitous. Aortic incompetence sometimes occurs in hypertension when necropsy shows no organic deformity of aortic ring or valve cusps (Garvin, 1940), whereas after pulmonary valvotomy the valve is grossly deformed and yet incompetence is rare. The higher pressures on the left side of the heart demand better valve function than is necessary at the pulmonary orifice. The valve in congenital aortic stenosis is initially more deformed and acquires grosser irregularity than in pulmonary stenosis. Even in young patients without calcification of the aortic valve, it would be over-optimistic to expect normal valve function even if the valve were divided under direct vision. This substitution of one disease by another can never be considered satisfactory therapy, especially when the severity of the disease produced is unpredictable. Although there was immediate evidence of aortic incompetence after completion of the valvotomy in two patients, there seems to us no advantage in the partial relief of the stenosis suggested by Bailey et al. (1954).

Assessment of the severity of the aortic incompetence produced is a prime consideration in any appreciation of the results of aortic valvotomy. In three patients the auscultatory evidence of 


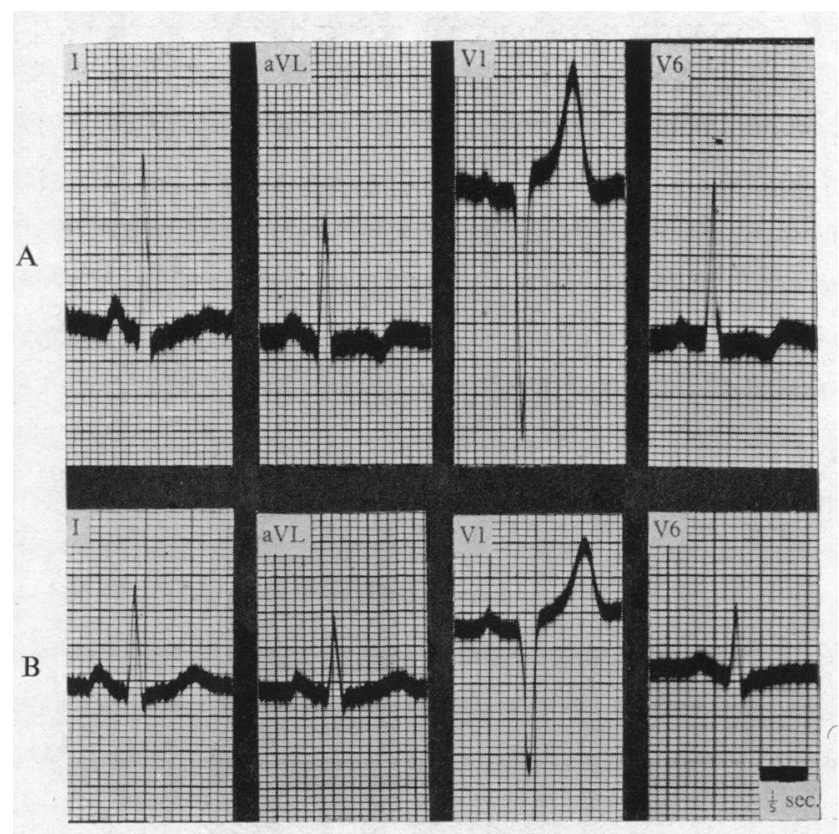

FIG. 15.-Electrocardiogram of Case 25. (A) Before valvotomy, showing left ventricular hypertrophy with $\mathrm{T}$ wave inversion in aVL and V6. (B) Six months after valvotomy, showing less left ventricular hypertrophy and $\mathrm{T}$ waves upright or flat instead of inverted in aVL and left chest leads (V6).

incompetence is accompanied by a collapsing peripheral pulse. The fact that intra-arterial pulse tracings in these patients show an increase in systolic pressure without a fall in diastolic pressure (Fig. 16) is of interest, but it would be a mistake at this stage to attach much importance to this observation. There was some increase in the heart size soon after the operation in all patients except one (Case 5): this was maximum three weeks after operation, and was sometimes very great (Fig. 14). In every case this enlargement decreased again between three weeks and three months after operation. There was further decrease by the sixth month, except in two patients with severe incompetence (Cases 16 and 22), whose hearts enlarged slightly between the third and sixth months after operation. When pulse pressure, heart size, and auscultatory signs are correlated, the aortic incompetence that followed the operation can be classified as severe in two patients (Case 16 and 22), moderate in two (Cases 11 and 12), and insignificant in one (Case 5).

It is clear that the results of valvotomy in congenital aortic stenosis are not always wholly beneficial and that they are to some extent unpredictable.

\section{ASSESSMENT FOR SURGERY}

The indications for valvotomy in congenital aortic stenosis appear much more restricted than they are in pulmonary stenosis and possibly in rheumatic aortic stenosis. The application of a major intra-cardiac operation which carries the additional danger of producing severe aortic incompetence is limited. On the basis of experience in pulmonary valvotomy, it seemed desirable to relieve aortic stenosis as soon as there was sufficient evidence of its severity (Marquis and Gilchrist, 1954). It was on this basis that our six patients were selected for the present pilot study. The possibility of recurrence of the stenosis must also influence the timing of operation. In order to reduce the need for a second operation and for the sake of making as large an orifice as possible, 


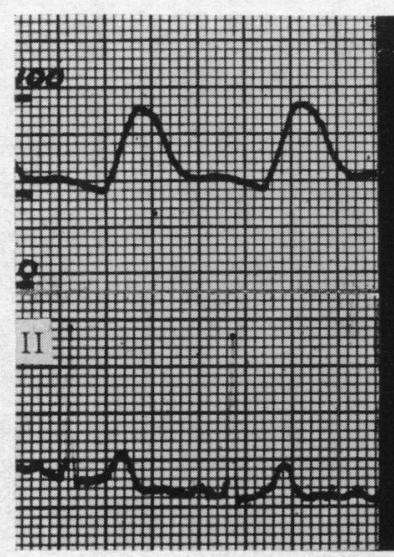

A

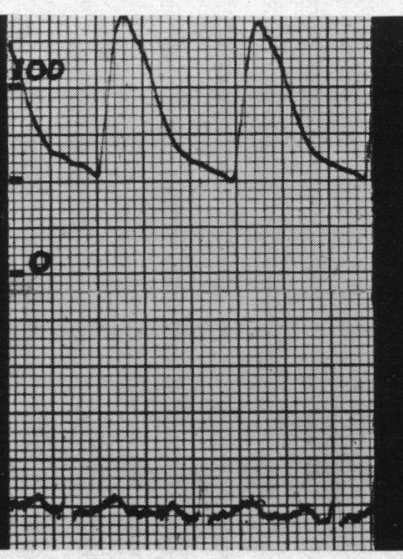

B

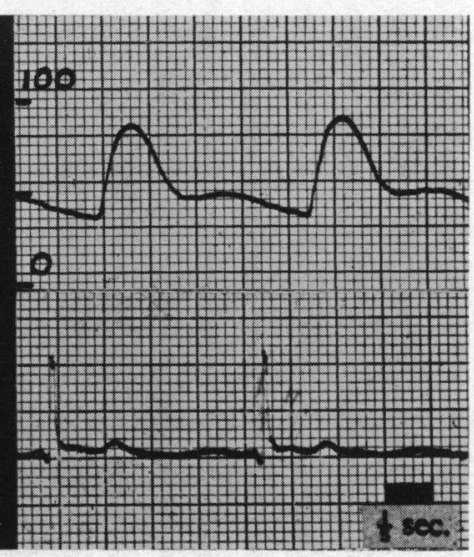

C

FIG. 16.-Intra-arterial femoral pulse wave in Case 16. (A) Before valvotomy B.P. 95/50; upstroke $0.16 \mathrm{sec}$. (B) Three weeks after valvotomy: B.P. 130/50; upstroke $0 \cdot 12 \mathrm{sec}$. (C) Normal control: B.P. 90/35; upstroke $0 \cdot 16 \mathrm{sec}$.

delay of operation until adult life is desirable if that is compatible with forestalling myocardial fibrosis, valve calcification, and death.

The final decision to operate must be based on the balance between the pre-operative risks of death and irreparable myocardial fibrosis on the one hard, and the risk of the operative procedure itself, and of post-operative aortic incompetence on the other.

The five patients, in whom there is now aortic incompetence, all show some objective evidence of improved cardiac function. Nevertheless in patients similar to Cases 16 and 22, we should now demand more evidence of increasing left ventricular strain, increasing heart size, cardiac syncope, or progressive disability before recommending operation. In patients similar to Case 12 , we should want a longer period of observation before deciding on surgery. In contrast, there would be no hesitation in recommending surgery to patients similar to Cases 5,11 , and 25, not because their results are comparatively good, but because their immediate prognosis was bad enough to justify operation in spite of the risk of severe aortic incompetence. Further experience in this type of patient may modify our present policy. It may be that the production of aortic incompetence will prove a lesser risk than progressive myocardial fibrosis. In the meantime, aortic valvotomy is not, in our opinion, justified in congenital stenosis except when there is a danger of sudden death or deterioration of a degree that might prejudice the outcome of postponed surgery. This situation appears to be present when there is electrocardiographic evidence of extreme left ventricular hypertrophy and strain in growing children. The finding of left ventricular strain is important at any age. If it is rapidly progressive, combined with increasing heart size or associated with undoubted hold-up of contrast medium on angiocardiography, it is probably dangerous to delay valvotomy. A history of cardiac syncope or of dizziness or breathlessness on exertion in these circumstaces stresses the urgency of operation.

\section{CONCLUSIONS AND SUMmaRY}

The course of 28 cases of congenital aortic stenosis is reviewed. The average period of observation was just under four years, during which five patients died.

The lack of symptoms and cardiac enlargement masks the frequency of the more severe grades of congenital aortic stenosis. The prognosis is less good than is widely believed. Once the diagnosis has been made in childhood, annual review is advisable if the warning signs of severity are to be recognized. Electrocardiographic evidence of increasing left ventricular hypertrophy and strain, especially in growing children, is the most reliable indication that the stenosis is severe. 
Severe aortic stenosis may lead to extensive fibrosis of the myocardium of the left ventricle, cardiac syncope, or sudden death, without the development of significant exertional dyspnœa.

The aortic stenosis in six of the patients reviewed was considered sufficiently severe to justify their inclusion in a pilot study of aortic valvulotomy. None died as a result of the operation. Their course during the subsequent six months is described. Valvotomy can result in greatly improved cardiac function in congenital aortic stenosis, but is liable to produce severe aortic incompetence. This limits its application to patients in whom the immediate prognosis is poor. In them valvotomy can prove a life-saving operation.

We wish to express our thanks to Dr. A. Rae Gilchrist for his help and encouragement in the preparation of this paper and for permission to report these cases; and to Professor Sir James Learmonth for every facility in the Department of Surgery.

\section{REFERENCES}

Abrahams, D. G., and Wood, P. (1951). Brit. Heart J., 13, 519.

Allenby, K. D., and Campbell, M. (1949). Guy's Hosp. Rep., 98, 18.

Anderson, M. W., Kelsey, J. R., and Edwards, J. E. (1952). J. Amer. med. Ass., 149, 9.

Bailey, C. P., Bolton, H. E., Jamieson, W. L., and Nichols, H. T. (1954). Circulation, 9, 22.

Bernheim, (1910). Rev. Médecine, 30, 785.

Brown, H. R., Marvin, J. H., and de Lalla, V. (1950). Circulation, 1, 132.

Brown, J. W. (1950). Congenital Heart Disease. St. Albans, Staples Press Limited.

Campbell, M., and Kauntze, R. (1953). Brit. Heart J., 15179.

Dry, T. J., and Willius, F. A. (1939). Amer. Heart J., 17, 138.

Fulton, W. F. M. (1954). Brit. Heart J., 16, 123.

Garvin, C. F. (1940). Ann. intern. Med., 13, 1799.

Green, H. D. (1936). Amer. J. Physiol., 115, 94.

Gregg, D. E. (1946). Physiol. Rev., 26, 28.

Grishman, A., Steinberg, M. F., and Sussman, M. L. (1947). Med. Clin. N. Amer., 31543.

Harrison, C. V., and Wood, P. (1949). Brit. Heart J., 11, 205.

Jacobs, H. D. (1954). Brit. Heart J., 16, 79.

Johnson, J. R., and di Palma, J. R. (1939). Amer. J. Physiol., 125, 234.

Kiloh, G. A. (1950). Brit. Heart J., 12, 33.

Larzelere, H. B., and Bailey, C. P. (1953). J. thorac, Surg., 26, 31.

Levine, S. A. (1945). Clinical Heart Disease. Philadelphia, W. B. Saunders Co.

(1949). Clinical Auscultation of the Heart. Philadelphia, W. B. Saunders Co.

Lewis, D. (1951). Brit. med. J., 1, 211 .

Logan, A., and Turner, R. W. D. (1954). Lancet, 1, 1091.

Marquis, R. M. (1951). Brit. Heart J., 13, 89.

, and Gilchrist, A. R. (1954). Trans. Med.-Chir. Soc. Edinb. (1953-54), Sessions 133, p. 31.

Marvin, H. M., and Sullivan, A. G. (1935). Amer. Heart J., 10, 705.

Peacock, T. B. (1865). Valvular Diseases of the Heart. J. Churchill \& Sons, London.

- (1868). Trans. Path. Soc. Lond., 19, 163.

Taussig, H. B. (1947). Congenital Malformation of the Heart. The Commonwealth Fund, New York. de Veer, J. A. (1938). Amer. Heart J., 15, 243.

Wiggers, C. J. (1949). Physiology in Health and Disease. 5th ed. London. Henry Kimpton. 